\title{
Determination of Knitted Fabric Porosity Using Digital Imaging Techniques
}

\author{
Manoj Kumar Imrith, Roshan Unmar, and Satyadev Rosunee \\ Department of Applied Sustainability \& Enterprise Development, Faculty of Engineering, University of Mauritius, Réduit, Mauritius \\ Correspondence should be addressed to Manoj Kumar Imrith; manoj.imrith@gmail.com
}

Received 27 July 2016; Revised 21 September 2016; Accepted 29 September 2016

Academic Editor: Nabil Ibrahim

Copyright ( 2016 Manoj Kumar Imrith et al. This is an open access article distributed under the Creative Commons Attribution License, which permits unrestricted use, distribution, and reproduction in any medium, provided the original work is properly cited.

\begin{abstract}
This paper has investigated the porosity of knitted fabrics using digital imaging techniques. A number of different methods have been proposed to determine the porosity of knitted fabrics, which include digital imaging, geometrical modeling, and air permeability. Digital imaging is an adequate technique to determine the porosity of high-porosity fabrics. In this work, eight types of knitted structures with eight different stitch lengths were produced on a flat-bed knitting machine. Porosity was determined using digital imaging techniques based on the method of threshold and pixel count, using a computer program developed for this work. The study consisted also of validating the results by including the data from two tested samples-from each set of knits throughout the use of regression equations which demonstrated that there is good correlation between the black mask and white mask images.
\end{abstract}

\section{Introduction}

The structure of a knitted fabric is vital as it provides several benefits. The fabric structure influences properties like comfort, drape, elasticity, and handling amongst many others.

Porosity of textiles is defined as a void part of the textile's full volume [1]. Furthermore, interyarn porosity, that is, the percentage void between the yarns of the knitted fabrics, is characterized by the pore dimension and distribution is a function of fabric geometry.

Previous theoretical studies of knitted fabric geometry focused on defining the shape of the loop. In geometrical models [2-4], the loop shape was first assumed and then geometrical parameters were adjusted to fit the experimental data. Knitted fabric structures consist of various cross sections. Based on his geometrical modeling work, Suh [4] assumed that yarns have uniform diameter and circular cross section while the curve parts of the loop represent the arc of a circle.

In addition, force analysis was used to investigate the mechanics of knitted fabrics [5-8]. Geometrical and physical principles were studied to assume the loop shape function, which was improved by adopting the buckled elastic rod theory [8]. However, empirical methods were still used to fit these models to experimental results $[4,8-10]$.
Karaguzel [11] calculated the pore size and pore volume values of plain knitted fabrics by using image analysis and fluid extrusion procedures. He deduced that there was a significant difference between the measured and estimated values. Using computer image analysis, Wilbik-Halgas et al. [12] studied the surface porosity of plain doubled-layered and lining knitted fabrics. It was concluded that transmission of air as opposed to water vapor through knitted fabrics is a function of the thickness and surface porosity.

Benltoufa Fayala et al. [13] used the method of geometry modeling for determining the porosity of jersey structures. Furthermore, Dias and Delkumburewatte [14] came forward with a theoretical model to predict the porosity of knitted fabric structures. They found that porosity depended on progression of relaxation and other fabric parameters.

Ogulata and Mavruz [15] affirmed that there are three main factors that influenced knitted fabric porosity:

(1) cross-sectional area of each pore;

(2) depth of each pore or the thickness of the fabric;

(3) the number of pores per unit area or the number of courses and wales per unit area.

The aim of this study is to use image analysis to assess the porosity of knitted fabrics produced on V-flat-bed knitting 


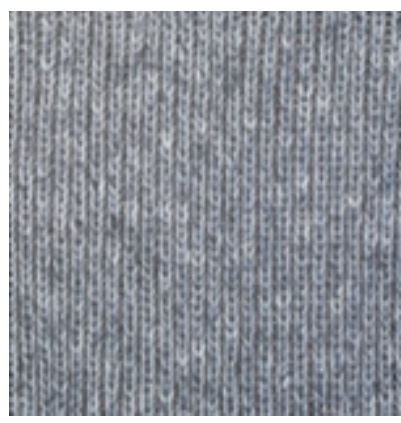

11

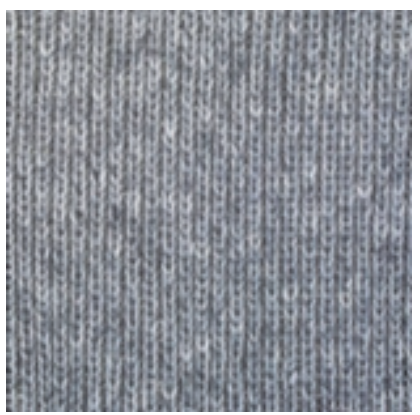

15

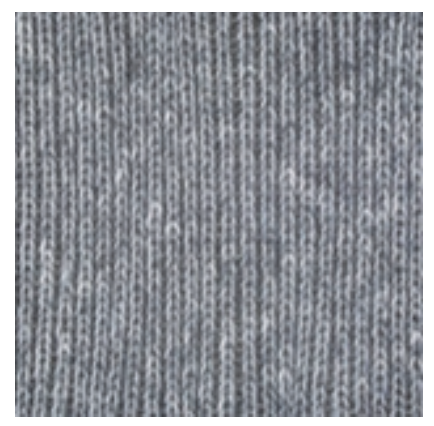

12

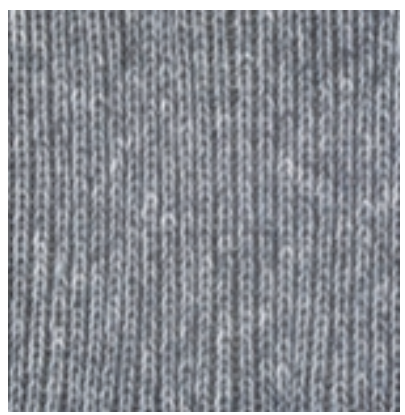

16

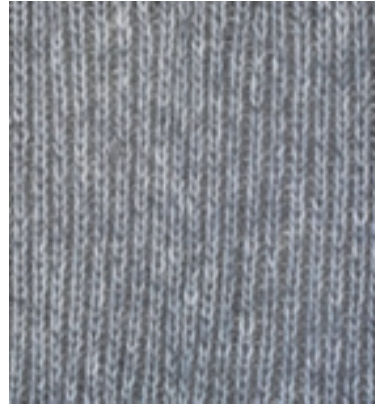

13

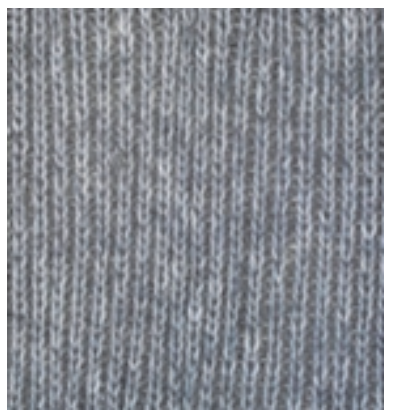

17

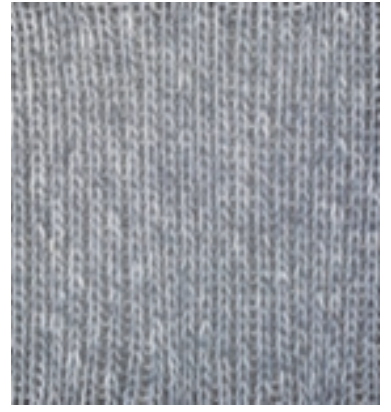

14

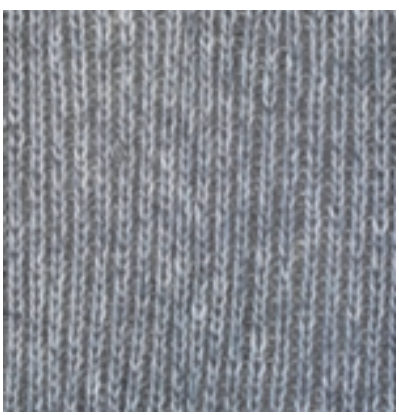

18

FIGURE 1: Rib $1 \times 1$ samples knitted at 8 stitch levels, starting from 11 to 18 .

machine (FKM). The knitting variables are loop length and stitch density.

\section{Materials and Methods}

2.1. Knitting. Investigations were carried out on four sets of knitted fabrics, namely, plain (double jersey), rib $1 \times 1$, rib $2 \times 1$, and single jersey. For plain fabrics, two sets of needles were used and the fabric is usually the same on the back side and face side. Plain fabrics do not have the tendency to curl. The face side and the backs side of rib $1 \times 1$ appear the same due to one vertical row of stitches that form on both of the faces. Rib $1 \times 1$ fabrics have the characteristic of high stretch. Similar to rib $1 \times 1$, the front and back sides of rib $2 \times 1$ are double faced and extensible but have two vertical rows. No curling occurs in rib $1 \times 1$ and rib $2 \times 1$ knits. Single-jersey knitted structures were made form single set of needles. Both sides of the fabric are distinct with fine ribs running in the course direction on the front side of the fabric and semicircular loops on the reverse. Examples of rib $1 \times 1$ are shown in Figure 1 .

A hand driven flat knitting machine was used to produce the samples:

machine brand: Flying Tiger;

gauge: $5 \mathrm{G}$;

length: 36 inches;

machine number: 0801879.

Woolen yarns of linear density $1.75 \mathrm{Ne}(355.5 \mathrm{Tex})$ were knitted on a 5-gauge knitting machine. The knitted fabrics were produced by varying the tension of the carriages at different consecutive 8 numbers (levels). The setting includes increasing or decreasing the carriage tension to vary the stitch length of the knitted samples. Table 1 shows the adjustment of the tensions values onto which each knitted sample was produced. Additionally, single-jersey fabrics were knitted on a circular knitting machine (CKM) at eight different stitch levels, with cotton yarn count $20 / 1 \mathrm{Ne}$, and subjected to similar testing carried out as for the flat-bed knits. Cotton jersey is the most frequent type of knit.

2.1.1. Determination of Wales per Inch (WPI), Course per Inch (CPI), and Stitch Density. The wales per inch (WPI) and course per inch (CPI) count of the knitted samples were measured according to ASTM D8007-15el [16]. The stitch density was calculated as follows:

$$
\text { Stitch Density }=\text { WPI } \times \text { CPI }
$$

(see [17]). Stitch length is theoretically the single length of yarn which includes one needle loop and half of a sinker loop between that needle loop and the adjacent needle loop. The length is measured in millimeters ( $\mathrm{mm})$. Postle [18] put forward a general formula to describe the tightness factor which was defined as below in (2). The tightness factor was calculated for the single-jersey structures by the given equation as follows:

$$
K=\frac{\sqrt{\mathrm{tex}}}{l},
$$

where tex is the linear density and $l$ is the stitch length $(A-B)$, measured in millimeters (Horrocks and Anand [19]). 
TABLE 1: Knitted samples fabric produced from varying the stitch cam value.

\begin{tabular}{|c|c|}
\hline Structure & Tension of carriage \\
\hline \multirow{8}{*}{ Plain } & 11 \\
\hline & 12 \\
\hline & 13 \\
\hline & 14 \\
\hline & 15 \\
\hline & 16 \\
\hline & 17 \\
\hline & 18 \\
\hline \multirow{8}{*}{ Rib $1 \times 1$} & 11 \\
\hline & 12 \\
\hline & 13 \\
\hline & 14 \\
\hline & 15 \\
\hline & 16 \\
\hline & 17 \\
\hline & 18 \\
\hline \multirow{8}{*}{ Rib $2 \times 1$} & 10 \\
\hline & 11 \\
\hline & 12 \\
\hline & 13 \\
\hline & 14 \\
\hline & 15 \\
\hline & 16 \\
\hline & 17 \\
\hline \multirow{8}{*}{ Single jersey } & 13 \\
\hline & 14 \\
\hline & 15 \\
\hline & 16 \\
\hline & 17 \\
\hline & 18 \\
\hline & 19 \\
\hline & 20 \\
\hline
\end{tabular}

\subsection{Determining the Percentage Voids (Porosity) Based on Digital Image Analysis}

2.2.1. Capturing the Images of Knitted Fabrics. Digital image analysis technique was used to measure the porosity of knitted fabric pictures and determining the pixel count of the images. The images were captured using a Fujifilm digital camera, 14.0 MP from assumed standard distance measured at $35 \mathrm{~cm}$ vertically between the camera lenses and the fabric sample, placed on a uniform white background. All images were captured during daytime whereby illumination of samples by sunlight may be assumed to be constant.

Thus the analysis of the two-dimensional images relies on processing the acquired images using a computer and digital image analysis software, MATLAB ${ }^{\circledR}$ R14. The captured images were then magnified by $12 \%$ using Adobe Photoshop, so that different areas of the samples' digital image could be subjected to analysis. The areas were selected at random.

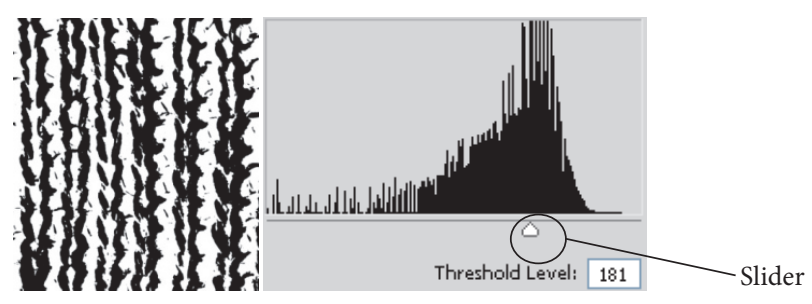

FIGURE 2: Black mask image.

2.2.2. Thresholding of Images. The actual measurements of porosity were done on binary images which consist of only two gray levels, obtained by using the gray level histograms in Adobe Photoshop. The gray levels above the mean were converted to black and all gray levels below the mean were converted to white. The difference between the yarn and the background was determined through thresholding. The RGB images were initially converted to gray scale and then to black and white monochromatic picture and finally to binary images with the help of the histogram. Initially, the binary image was completely white. With the help of the "minimum" option, black pixels were added to the image to mimic the real image. In due course, the appearance of the knitted fabric was compared to the real image.

Firstly, a "white mask" image was obtained showing the yarns as white and the resulting background as black. Then the black mask image was secured showing the yarns as black and the background as white.

2.2.3. Determining the Pixel Count. After securing distinct outlines of the "white mask" and "black mask" images, respectively, the number of pixels for each of the images was determined. For example, for the "white mask" images, the areas occupied by the yarns were seen as white while the pore areas were seen as black. Exactly the same procedure was adopted for the processing of "black mask" images. A Pixel Count algorithm was written in M-File, MATLAB, to quantify the amount of black or white pixels in the binary images. The pixel count algorithm detects the quantity of black or white pixels depending on the threshold value set in the algorithm.

For instance, Figures 2 and 3 are the black mask and white mask images, respectively, of the rib $1 \times 1$ fabric at stitch cam 15; threshold value is 181 for both images, which means that the range 181-255 represents the black regions for both images. Therefore, threshold value $0-181$ represents the white regions of the images.

Figures 2 and 3 show rib $1 \times 1$ fabric at stitch cam 15 with threshold value 181 for CKM and the macroscopic view of single-jersey structure form FKM is shown in Figure 4. The threshold leveling histograms are shown next to each fabric sample. The threshold values varied for the different types of knitted samples. The slider as shown in Figures 2 and 3 was moved until distinct images of the yarns were observed.

The histogram graphs of the images represent the tonal range of the images that is the images' brightness values. The histograms are also indicating how much of the image is actually pure black (the highest point of the brightness 


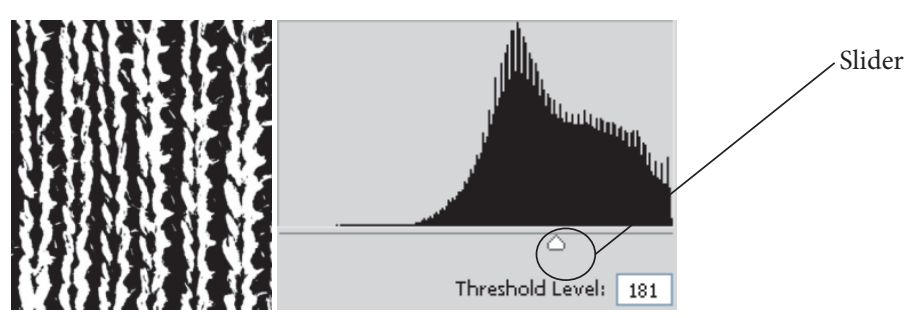

Figure 3: White mask image.
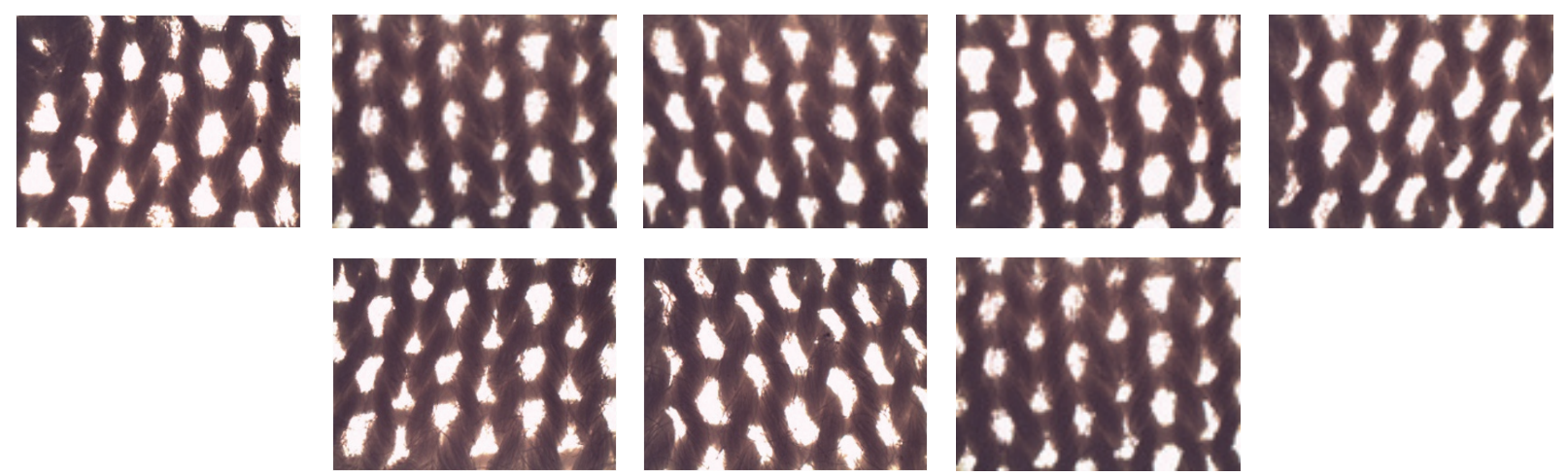

FIGURE 4: Macroscopic view of the 8 single-jersey knitted samples from CKM.

of an image) and the quantity that falls between black and white. As shown in Figures 2 and 3, the histogram is the black "mountain range." This implies that the higher the histogram appears over a certain brightness level in the gradient, the more distinct are the outlines of the image. The lower the histogram is over a certain brightness level in the gradient, the less of the image appears at that brightness level.

Firstly the pixel count of the black region for both white masked and black masked sets of images was determined with the help of the algorithm. The set threshold values were minimum 165 and maximum 255, meaning that the algorithm computes the number of black pixels within that threshold range. This procedure was repeated for all fabric images together with their respective threshold values.

Then the pixel count of white region was calculated. In this case, the minimum value was zero and maximum 181. Thus the algorithm computes the pixel count of only the white areas in the image. This procedure was repeated for all fabric images as mentioned previously. The pixel count values were recorded, respectively, for the knits as shown in Tables 2 and 3. The images being a two-dimensional matrix of real/imaginary numbers being presented by a definite number of bytes provide the pixel count values for the white mask images and black mask images, respectively.

The Algaba [20] equation was used to obtain the percentage cover for both black mask and white mask images, as follows:

Percentage Cover for Black Mask Images

$$
=\frac{\left(\mathrm{BM}_{1} /\left(\mathrm{WM}_{1}+\mathrm{BM}_{1}\right)\right)+\left(\mathrm{BM}_{2} /\left(\mathrm{WM}_{2}+\mathrm{BM}_{2}\right)\right)}{2}
$$

$\times 100$,
Percentage Cover for White Mask Images

$$
\begin{aligned}
= & \frac{\left(\mathrm{WM}_{1} /\left(\mathrm{WM}_{1}+\mathrm{BM}_{1}\right)\right)+\left(\mathrm{WM}_{2} /\left(\mathrm{WM}_{2}+\mathrm{BM}_{2}\right)\right)}{2} \\
& \times 100,
\end{aligned}
$$

where $\mathrm{BM}_{1}$ is black mask for zone $1, \mathrm{BM}_{2}$ is black mask for zone $2, \mathrm{WM}_{1}$ is white mask for zone 1 , and $\mathrm{WM}_{2}$ is white mask for zone 2 .

\section{Results and Discussion}

Fabric properties (stitch length, course count per $\mathrm{cm}$, and wale count per $\mathrm{cm}$ ) and the experimental porosity values measured are presented in Tables 2 and 3 for FKM and CKM knits, respectively. Since the wale count per $\mathrm{cm}$ normally depends on the machine settings, the porosity values would vary. From the two tables, the fabrics having the lower course count per $\mathrm{cm}$ have the higher the percentage porosity. Therefore, increasing the stitch levels resulted in looser fabrics, thereby increasing the porosity. Microscopic views of the pores were observed for the single-jersey CKM structures from pictures taken using a digital microscope.

3.1. Effect of Knit Parameters on Pore Size. Image analysis was used to measure the pore size (porosity) as well as assess the percentage porosity of the samples. MATLAB was used to obtain the areas of individual pores detected with pixels. Firstly, the black pixels were calculated for the black mask and white mask images; then the white mask images were calculated. The percentage of porosity was then calculated. 
TABLE 2: Results of fabric structural parameters of FKM knitted samples and image analysis results of percentage of void values of black and white region of images of fabric.

\begin{tabular}{|c|c|c|c|c|c|c|c|}
\hline Structures & $\begin{array}{l}\text { Tension of } \\
\text { carriage }\end{array}$ & $\begin{array}{l}\text { Course per } \\
\text { inch }\left(K_{c}\right)\end{array}$ & $\begin{array}{l}\text { Wales per } \\
\text { inch }\left(K_{w}\right)\end{array}$ & $\begin{array}{l}\text { Stitch density } \\
\left(K_{s}\right)\end{array}$ & $\begin{array}{l}\text { Stitch length, } \\
\quad l(\mathrm{~mm})\end{array}$ & $\begin{array}{c}\text { Porosity } \\
\text { (white mask) } \\
(\%)\end{array}$ & $\begin{array}{c}\text { Porosity } \\
\text { (black mask) } \\
(\%)\end{array}$ \\
\hline \multirow{8}{*}{ Plain } & 11 & 1.2 & 1.64 & 1.96 & 9.4 & 48.2 & 48.3 \\
\hline & 12 & 1.02 & 1.57 & 1.6 & 10.5 & 49.7 & 49 \\
\hline & 13 & 0.98 & 1.46 & 1.43 & 10.7 & 50.1 & 49.2 \\
\hline & 14 & 0.9 & 1.34 & 1.21 & 11.4 & 50.5 & 49.7 \\
\hline & 15 & 0.88 & 1.31 & 1.15 & 11.8 & 51.9 & 50.3 \\
\hline & 16 & 0.83 & 1.29 & 1.07 & 12 & 52.2 & 50.4 \\
\hline & 17 & 0.72 & 1.15 & 0.82 & 13.9 & 54.8 & 51.3 \\
\hline & 18 & 0.61 & 0.8 & 0.49 & 14.2 & 55.4 & 51.8 \\
\hline \multirow{8}{*}{ Rib $1 \times 1$} & 11 & 1.1 & 1.77 & 1.95 & 10.5 & 49.1 & 49.2 \\
\hline & 12 & 1.02 & 1.65 & 1.68 & 12.8 & 49.5 & 49.7 \\
\hline & 13 & 0.98 & 1.61 & 1.58 & 13.8 & 49.6 & 50.5 \\
\hline & 14 & 0.91 & 1.5 & 1.37 & 15.5 & 49.7 & 50.8 \\
\hline & 15 & 0.85 & 1.47 & 1.25 & 16 & 50.1 & 51 \\
\hline & 16 & 0.81 & 1.41 & 1.4 & 16.8 & 51.1 & 52.4 \\
\hline & 17 & 0.75 & 1.38 & 1.14 & 17.3 & 51.2 & 52.5 \\
\hline & 18 & 0.7 & 1.32 & 0.92 & 17.9 & 53.1 & 53.4 \\
\hline \multirow{8}{*}{ Rib $2 \times 1$} & 10 & 1.04 & 1.68 & 1.74 & 11.9 & 43.2 & 40.1 \\
\hline & 11 & 1.01 & 1.52 & 1.54 & 12.4 & 45.1 & 42.2 \\
\hline & 12 & 0.92 & 1.44 & 1.32 & 13.8 & 45.2 & 44.1 \\
\hline & 13 & 0.81 & 1.41 & 1.14 & 14.2 & 47.7 & 49.1 \\
\hline & 14 & 0.91 & 1.38 & 1.26 & 15.2 & 48.9 & 49.2 \\
\hline & 15 & 0.87 & 1.26 & 1.09 & 15.7 & 49.3 & 50.4 \\
\hline & 16 & 0.83 & 1.2 & 0.99 & 16.3 & 50 & 51.4 \\
\hline & 17 & 0.79 & 1.17 & 0.92 & 16.7 & 51.3 & 51.6 \\
\hline \multirow{8}{*}{ Single jersey } & 13 & 1.18 & 1.48 & 1.75 & 11.9 & 44.2 & 47.2 \\
\hline & 14 & 1.16 & 1.44 & 1.67 & 13.1 & 45.3 & 48.1 \\
\hline & 15 & 1.12 & 1.42 & 1.6 & 13.6 & 47 & 48.7 \\
\hline & 16 & 1.08 & 1.4 & 1.51 & 14.1 & 51 & 49 \\
\hline & 17 & 1.06 & 1.38 & 1.46 & 14.4 & 51.3 & 49.1 \\
\hline & 18 & 0.98 & 1.3 & 1.27 & 16.6 & 53.5 & 49.6 \\
\hline & 19 & 0.86 & 1.28 & 1.1 & 17.2 & 54.9 & 53.4 \\
\hline & 20 & 0.62 & 1.2 & 0.74 & 18.6 & 55.2 & 54.1 \\
\hline
\end{tabular}

TABLE 3: Results of fabric structural parameters and image analysis pixel count and percentage of void values of single-jersey fabric (CKM samples).

\begin{tabular}{|c|c|c|c|c|c|c|c|}
\hline $\begin{array}{l}\text { Single-jersey } \\
\text { sample }\end{array}$ & $\begin{array}{l}\text { Course per } \\
\text { inch }\left(K_{c}\right)\end{array}$ & $\begin{array}{l}\text { Wales per } \\
\text { inch }\left(K_{w}\right)\end{array}$ & $\begin{array}{l}\text { Stitch density } \\
\left(K_{s}\right)\end{array}$ & $\begin{array}{c}\text { Stitch length, } \\
l\end{array}$ & $\begin{array}{l}\text { Tightness } \\
\text { factor }\end{array}$ & $\begin{array}{c}\text { Porosity } \\
\text { (white mask) } \\
(\%)\end{array}$ & $\begin{array}{c}\text { Porosity } \\
\text { (black mask) } \\
(\%)\end{array}$ \\
\hline 1 & 4.8 & 6.5 & 31.2 & 3 & 2.86 & 47.2 & 44.4 \\
\hline 2 & 4.6 & 6.3 & 29 & 3.1 & 2.82 & 48.5 & 45 \\
\hline 3 & 4.4 & 5.8 & 25.5 & 3.3 & 2.73 & 49.1 & 49.5 \\
\hline 4 & 4.3 & 5.7 & 24.5 & 3.5 & 2.65 & 51.7 & 51.3 \\
\hline 5 & 4 & 5.6 & 23.5 & 3.6 & 2.61 & 52.2 & 51.5 \\
\hline 6 & 3.8 & 5.3 & 20.1 & 3.8 & 2.54 & 52.8 & 53 \\
\hline 7 & 3.7 & 5.1 & 18.9 & 3.9 & 2.51 & 53.1 & 53.8 \\
\hline 8 & 3.5 & 4.8 & 16.8 & 4.2 & 2.42 & 53.9 & 54.2 \\
\hline
\end{tabular}




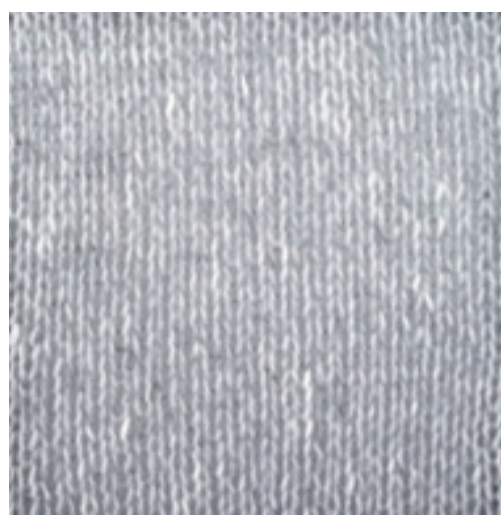

(a)

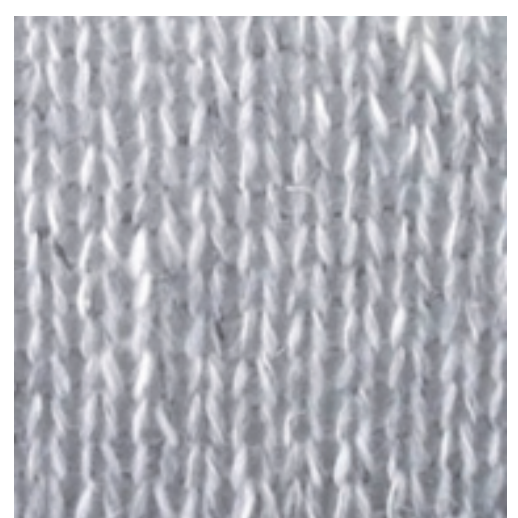

(b)

FIGURE 5: (a) Unmagnified single-jersey structure image. (b) Magnification (12\%).

TABLE 4: Fabric features knitted for testing and validation and percentage of error for the porosity against stitch length of white and black mask images (FKM samples).

\begin{tabular}{|c|c|c|c|c|c|c|c|c|}
\hline Structures & $\begin{array}{l}\text { Stitch cam } \\
\text { values }\end{array}$ & $\begin{array}{l}\text { Stitch length, } \\
\quad l(\mathrm{~mm})\end{array}$ & $\begin{array}{c}\text { Porosity } \\
\text { (white mask) } \\
(\%)\end{array}$ & $\begin{array}{c}\text { Porosity } \\
\text { (black mask) } \\
(\%)\end{array}$ & $\begin{array}{c}\text { Model values } \\
\text { (white mask) } \\
(\%)\end{array}$ & $\begin{array}{c}\text { Model values } \\
\text { (black mask) } \\
(\%)\end{array}$ & $\begin{array}{c}\text { Error (white } \\
\text { mask) (\%) }\end{array}$ & $\begin{array}{c}\text { Error (black } \\
\text { mask) (\%) }\end{array}$ \\
\hline \multirow{2}{*}{ Plain } & 19 & 15.1 & 55.8 & 52.1 & 56.7 & 52.4 & 1.61 & 0.58 \\
\hline & 20 & 15.7 & 56.9 & 52.2 & 57.6 & 52.8 & 1.23 & 0.57 \\
\hline \multirow{2}{*}{ Rib $1 \times 1$} & 19 & 18.8 & 54.9 & 55 & 52 & 53.2 & -5.28 & -3.27 \\
\hline & 20 & 19.5 & 56 & 55.8 & 52.3 & 53.6 & -6.61 & -3.94 \\
\hline \multirow{2}{*}{ Rib $2 \times 1$} & 18 & 17.6 & 53 & 52.7 & 52.3 & 54.7 & -1.32 & 1.97 \\
\hline & 19 & 18.9 & 53.8 & 54.7 & 54.4 & 58 & 1.11 & 6.03 \\
\hline \multirow{2}{*}{ Single jersey } & 21 & 19.9 & 57.6 & 57.2 & 59 & 55 & 2.43 & -3.85 \\
\hline & 22 & 22 & 59.9 & 58.8 & 62.7 & 57 & 4.67 & -3.06 \\
\hline
\end{tabular}

TABLE 5: Fabric features knitted for testing and validation (CKM samples).

\begin{tabular}{|c|c|c|c|c|c|}
\hline $\begin{array}{l}\text { Single-jersey } \\
\text { sample }\end{array}$ & $\begin{array}{l}\text { Stitch density } \\
\qquad\left(K_{s}\right)\end{array}$ & $\begin{array}{c}\text { Stitch length, } \\
l\end{array}$ & $\begin{array}{l}\text { Tightness } \\
\text { factor }\end{array}$ & $\begin{array}{c}\text { Porosity } \\
\text { (white mask) } \\
(\%)\end{array}$ & $\begin{array}{c}\text { Porosity } \\
\text { (black mask) } \\
(\%)\end{array}$ \\
\hline 9 & 14.1 & 4.6 & 2.31 & 55.4 & 55.1 \\
\hline 10 & 11.6 & 4.8 & 2.26 & 56.2 & 57.3 \\
\hline
\end{tabular}

The basic structural parameters and the percentage porosity values obtained from image analysis system for all sets of samples are enumerated in Tables 2 and 3. It can be observed from both tables that the percentage porosity values decreased with increase in course density. The image analysis results show that pore size increased with increase in stitch cam levels, which must be due to the increase in stitch density.

The effect of magnifying of the images of fabric structures is shown in Figure 5. A single-jersey structure (stitch cam 15) is illustrated as example.

The grayscale images of the magnified samples would allow determination of the area occupied by the black and white mask, which would in turn provide the information about percentage void. The measured percentage porosity values using image analysis algorithm are then related to the fabric geometry of the fabrics. The values are given in Tables 4 and 5 .
3.2. Effect of Fabric Tightness. The tightness factor is the parameter which measures the tightness of the fabric; that is, with an increase in tightness (or decrease in slackness), the tightness factor of the knitted structure increases. Fabric tightness is a parameter which shows the level of tightness in a knitted fabric. The interyarn pores will potentially be smaller in fabrics knitted at high stitch lengths.

As shown in Table 2, the lowest stitch lengths for the set of structures show low porosity values. Moreover, these increase gradually as the stitch cams were adjusted to higher values, and consequently the loops' size increases. Thresholding the images provides a virtual reality to binary image giving reliable white and black mask count values.

3.3. Regression and Correlation. For each fabric type, the first eight sets of values were fed into an Excel worksheet to obtain the linear regression equations and correlation values. The 
TABLE 6: Linear regression equations: \% porosity against stitch length (FKM samples).

\begin{tabular}{|c|c|c|c|c|c|}
\hline Fabric features & Structures & White mask & $R^{2}$ value & Black mask & $R^{2}$ value \\
\hline \multirow{4}{*}{$\%$ porosity $(P)$, stitch length $(\mathrm{SL})$} & Plain & $\% P=1.509(\mathrm{SL})+33.88$ & 0.989 & $\% P=0.711(\mathrm{SL})+41.65$ & 0.980 \\
\hline & Rib $1 \times 1$ & $\% P=0.426(\mathrm{SL})+43.99$ & 0.669 & $\% P=0.5439(\mathrm{SL})+42.99$ & 0.884 \\
\hline & Rib $2 \times 1$ & $\% P=1.551(\mathrm{SL})+25.05$ & 0.945 & $\% P=2.437(\mathrm{SL})+11.85$ & 0.924 \\
\hline & Single jersey & $\% P=1.763(\mathrm{SL})+23.95$ & 0.877 & $\% P=1.011(\mathrm{SL})+34.79$ & 0.864 \\
\hline
\end{tabular}

TABLE 7: Linear regression equations—-for the different features for the CKM knits.

(a)

\begin{tabular}{lcc}
\hline Fabric features & Single jersey & $R^{2}$ value \\
\hline Tightness factor, stitch length (SL) & $\mathrm{TF}=-0.372(\mathrm{SL})+3.966$ & 0.993 \\
\hline
\end{tabular}

(b)

\begin{tabular}{|c|c|c|c|c|}
\hline \multirow{2}{*}{ Fabric features } & \multicolumn{4}{|c|}{ Single jersey } \\
\hline & White mask & $R^{2}$ value & Black mask & $R^{2}$ value \\
\hline$\% P, \mathrm{SL}$ & $\% P=5.75(\mathrm{SL})+30.65$ & 0.923 & $\% P=8.707(\mathrm{SL})+19.42$ & 0.888 \\
\hline$\% P$, SD & $\% P=-0.473(\mathrm{SD})+62.28$ & 0.912 & $\% P=-0.736(\mathrm{SD})+67.79$ & 0.926 \\
\hline$\% P, \mathrm{TF}$ & $\% P=-15.61(\mathrm{TF})+92.31$ & 0.952 & $\% P=-23.81(\mathrm{TF})+113.2$ & 0.930 \\
\hline
\end{tabular}

ninth and tenth sets were used for validation as shown in Tables 6 and 7, respectively.

\subsection{Results for FKM Samples}

3.4.1. Effect of Stitch Length on Percentage Porosity. The percentage porosity was plotted against the stitch length. It shows that, for the knitted structures, the correlation is high for black mask images $\left(R^{2}=0.980\right.$ for plain, $R^{2}=0.884$ for rib $1 \times 1, R^{2}=0.924$ for rib $2 \times 1$, and $R^{2}=0.864$ for single jersey). Therefore, the correlation values, $R$, obtained from the statistical assessment are close without much variation.

Figures 6-9 also show the influence of the stitch length on percentage porosity. For rib $1 \times 1$ rather poor correlation was observed as $R^{2}$ value for white mask image $=0.669$ and for black mask image $=0.884$.

3.4.2. Validating Correlation and Regression. Table 6 shows the correlation values for the different parameters and experimental values involved for FKM knits.

3.5. Results for CKM Single-Jersey Samples. From Figures 10 and 11 it can be concluded that the stitch length is inversely proportional to the tightness factor. Percentage porosity decreases for increasing tightness factor whereas the percentage of porosity increases for increasing stitch length.

The values indicate that the correlation is superior for the black mask images to the white mask ones. At this point, it is necessary to observe the trend. The influence of stitch length on percentage porosity is significant because the correlation index $R^{2}=0.930$ (for black mask) with a slight increase for the white mask at $R^{2}=0.952$.

Figure 12 represents the percentage of porosity against stitch density and Figure 13 represents the tightness factor against stitch length. It shows that the stitch density is inversely proportional to porosity and tightness factor is

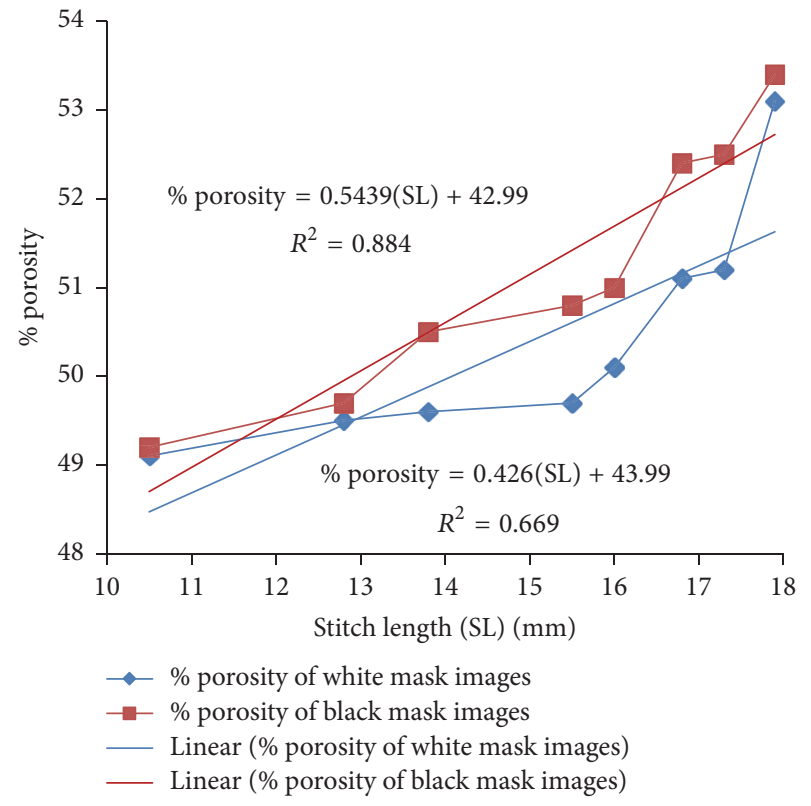

FIGURE 6: Percentage porosity against stitch length (SL) for rib $1 \times 1$ structure for FKM.

inversely proportional to stitch length, respectively. It must also be emphasized that in most cases black mask images correlate more than white mask images. In fact, an increase in the stitch density implies a reduction in the volume of pores in knitting and so a reduction in porosity. However, the loop length also has an impact on the stitch density. The porosity values follow the trend of the predicted model values.

3.6. Experimental Results Used for Validation. Further data was generated from two sets of identical knitted fabrics for the 


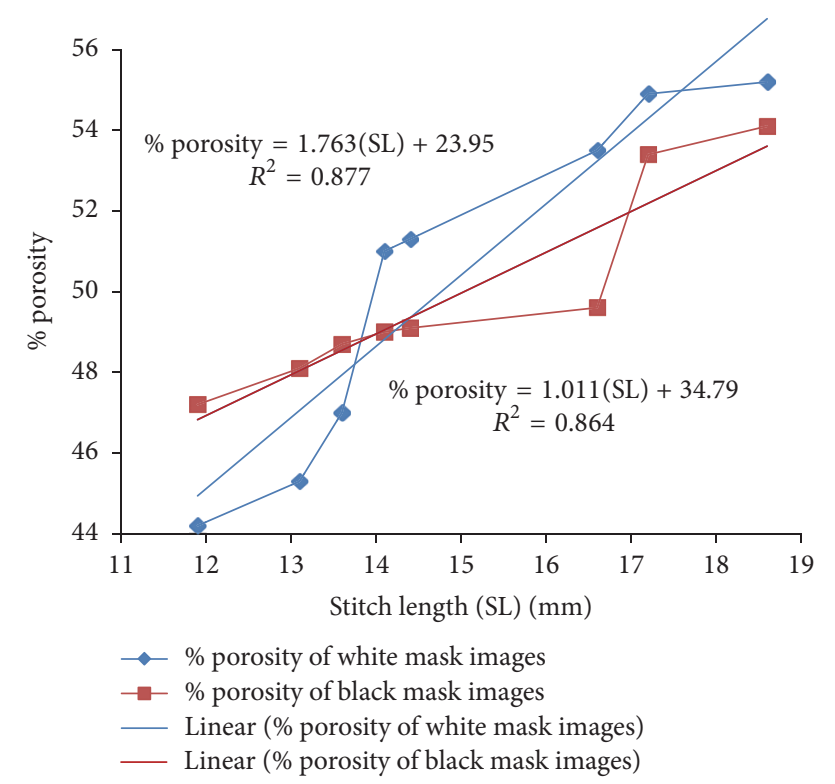

FIGURE 7: Percentage porosity against stitch length (SL) for singlejersey structure for FKM.

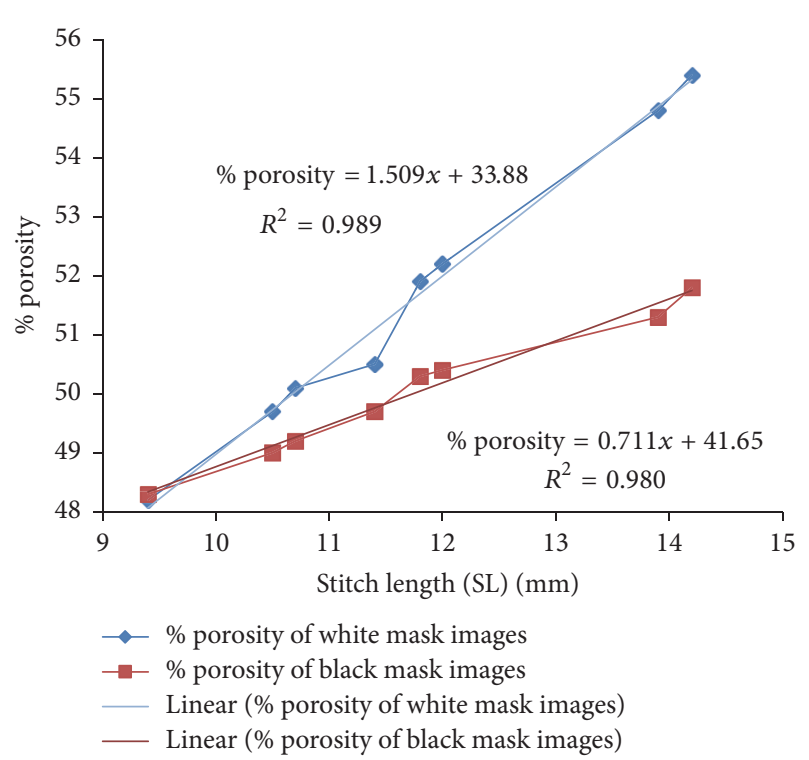

FIGURE 8: Percentage porosity against stitch length (SL) for plain structure for FKM.

purpose of validation as shown in Tables 7 and 8, respectively. The values generated were fed into the regression equations.

3.7. Modeling. The model values of percentage porosity are calculated by substituting the knitting parameters in the equations in Tables 3 and 4 . For the calculation of the model values, the percentage of porosity and the stitch length of the knitted fabrics are taken into consideration. These two items, as indicated previously, are the main factors that acted as the main agent in determining fabric porosity. The model values of ninth and tenth knitted tested samples experimental values of the $\%$ porosity against the $\%$ characteristics of the

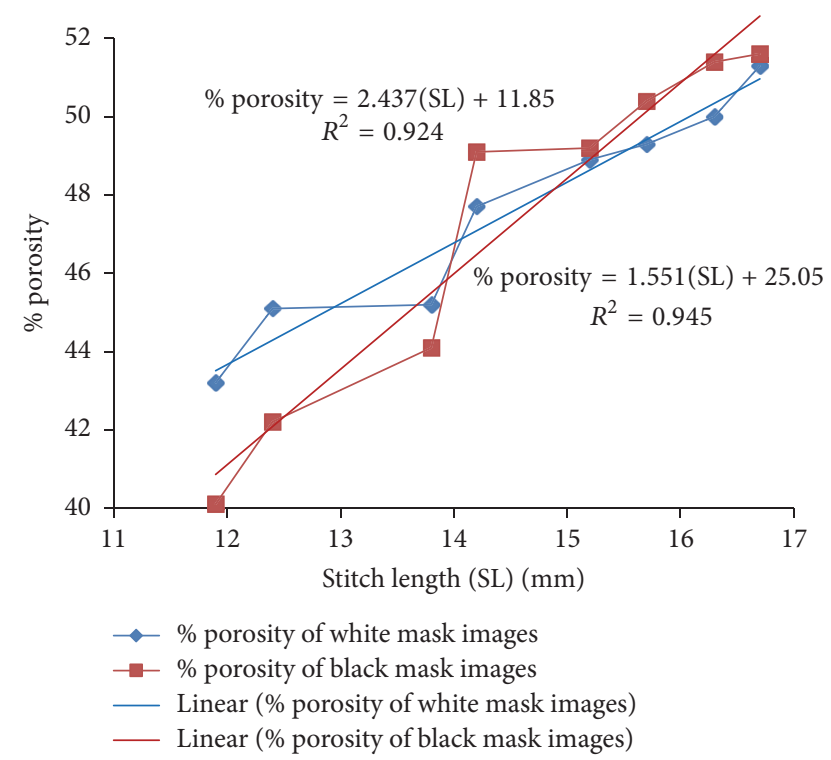

FIGURE 9: Percentage porosity against stitch length (SL) for rib $2 \times 1$ for FKM.

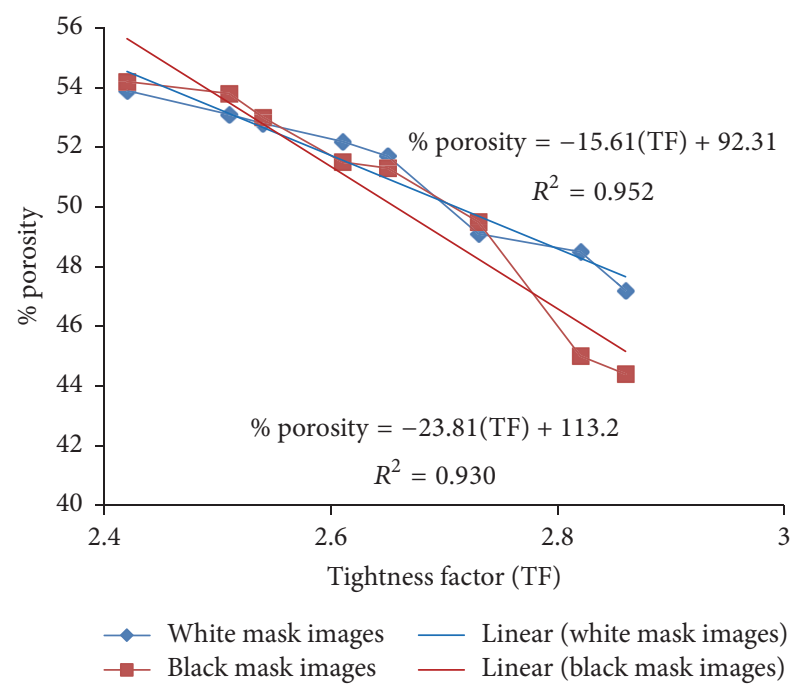

FIGURE 10: \% porosity against TF for CKM.

fabrics were computed. Following that, the percentage error was calculated.

The percentage error for the additional knitted samples is shown (Table 8).

\subsection{Predictive Model of the Knitted Fabric Porosity Parameters.} Tables 4 and 8 present the comparison of the experimental and predicted values of the porosity parameters. Percent errors are usually taken at their absolute values; the positive percentage errors indicate that the experimental values are too high and the negative numbers show that the experimental values are too low. The negative percent errors mean that the observed results are lower than the expected. Arguably, it is stated that a negative error could mean the same thing as the positive error. For example, if there is a chance of making 
TABLE 8: The calculated percentage of error (CKM samples).

\begin{tabular}{|c|c|c|c|c|c|c|c|}
\hline \multirow{3}{*}{$\begin{array}{l}\text { Fabric features } \\
\text { Samples }\end{array}$} & \multicolumn{7}{|c|}{ Single jersey } \\
\hline & \multirow{2}{*}{ Masking } & \multicolumn{2}{|c|}{ Expt. value (\% porosity) } & \multicolumn{2}{|c|}{ Model values } & \multicolumn{2}{|c|}{ Error (\%) } \\
\hline & & 9 & 10 & 9 & 10 & 9 & 10 \\
\hline \multirow{2}{*}{$\%(P),(\mathrm{SL})$} & White & 55.4 & 56.2 & 57.1 & 58.3 & 3.07 & 3.75 \\
\hline & Black & 55.1 & 57.3 & 59.5 & 61.2 & 7.98 & 6.81 \\
\hline \multirow{2}{*}{$\%(P),(\mathrm{SD})$} & White & 55.4 & 56.2 & 55.6 & 56.8 & 0.36 & 1.07 \\
\hline & Black & 55.1 & 57.3 & 57.4 & 59.3 & 4.17 & 3.49 \\
\hline \multirow{2}{*}{$\%(P),(\mathrm{TF})$} & White & 55.4 & 56.2 & 56.3 & 57 & 1.62 & 1.42 \\
\hline & Black & 55.1 & 57.3 & 58.2 & 59.4 & 5.63 & 3.66 \\
\hline
\end{tabular}
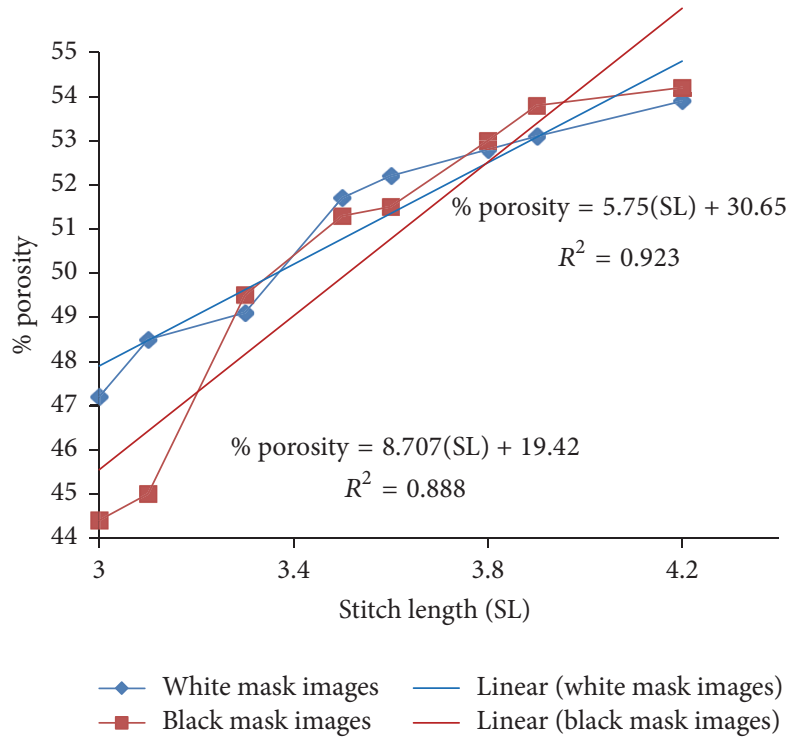

FIGURE 11: \% porosity against SL for CKM.

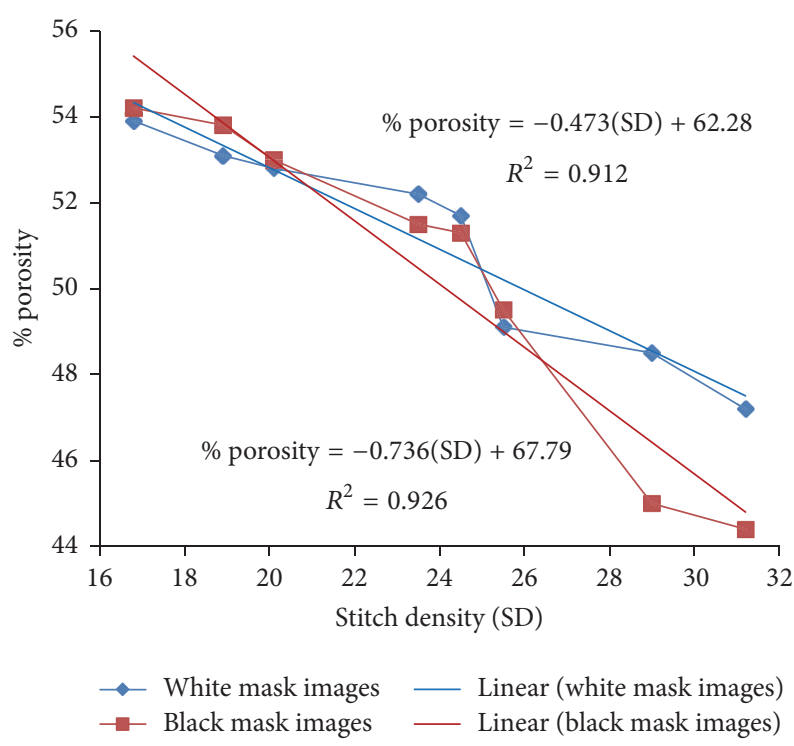

FIGURE 12: \% porosity against SD for CKM.

a $25 \%$ error and a $-7 \%$ error, then the negative percent error is more accurate. The percentage errors for some samples are

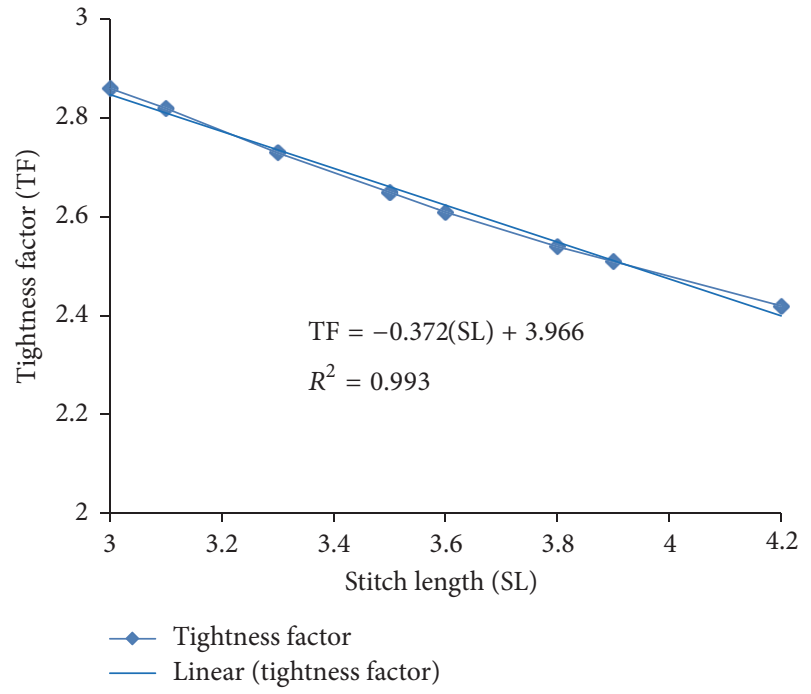

FIGURE 13: Tightness factor against stitch length for CKM.

not in good agreement and some are much above $(6.03 \%$ for rib $2 \times 1$ CKM) and some below at -3.94 than zero. The reason may lie in the fact that these samples were threshold, so that blackening occurred within the image. The result in Table 4 shows that the model values of porosity parameters deviate from the experimental ones by percentage error ranging from 6.03 to -3.94 . On the contrary the FKM knit samples, Table 8, do not exhibit much variation in their values, but major deviation can be observed at values 7.98 and 6.81 for porosity against stitch length.

This work shows that porosity may be predicted if the stitch length of the knitted fabric is known. These results show basically that the aforementioned statement on percentage error is compatible with the correlation values obtained from the graphs. The samples which demonstrate that the percentage error is negative mean that there is more accuracy in the negative percent error. Some values show near to $0 \%$ error, for instance, the percentage porosity for the black mask images, for the plain structure in Table 4. Single jersey for porosity against stitch density also shows 0.36 error for percentage porosity against stitch length. Thus, the analysis generally shows that the use of the black mask images will be more reliable in predicting the porosity. 


\section{Conclusion}

The prevailing purpose of this work was to use digital image analysis to determine the porosity of knitted fabrics. Determining what porosity means and the factors influencing it in knitted fabrics may find its application in sun-protecting clothes and thermophysiological comfort of textiles. The results obtained by measuring the number of pixels in a given category of gray scale are compatible with the model values obtained throughout the validation exercise. The tighter the knitted specimens the smaller the pores. Increasing the stitch cam result in higher loop length and looser structure. The main advantage of using digital image analysis to assess porosity of textiles is that there is greater accuracy and higher reproducibility. Digital image analyses of textiles provide simple, systematic, and proficient methodology for determining the porosity. In addition image correction techniques such as gray scaling and thresholding allow for an evident identification of the knitted structures. It is however recommended to determine fabric porosity through structural modeling. An interesting further research project is to implement the concept of biomimicry. Using the concept of reverse engineering, organisms which exhibit anti-UVR features can be studied. The characteristics can be simulated and transposed onto textile surfaces. Since biomimicry is related to sustainability, this approach seems to be well motivated in line with the concept. A fresh field of textile can therefore be developed with desired properties of anti-UVR and comfort.

\section{Competing Interests}

The authors declare that there is no conflict of interests regarding the publication of this paper.

\section{References}

[1] D. Jakšić and N. Jakšić, "Woven fabric engineering," in Porosity of the Flat Textiles, chapter 14, 2010.

[2] G. A. Leaf and A. Glaskin, "The geometry of a plain knitted loop," Journal of the Textile Institute Transactions, vol. 46, no. 9, pp. T587-T605, 1955.

[3] F. T. Pierce, "Geometrical principles applicable to the design of functional fabrics," Textile Research Journal, vol. 17, pp. 123-147, 1947.

[4] M. W. Suh, "A Study of the Shrinkage of Plain Knitted Cotton Fabric, Based on the structural changes of the loop geometry due to yarn swelling and deswelling," Textile Research Journal, vol. 37, no. 5, pp. 417-431, 1967.

[5] B. Hepworth and G. A. V. Leaf, "Mechanics of an idealized weftknitted structure," Journal of the Textile Institute, vol. 67, no. 7-8, pp. 241-248, 1976.

[6] B. Hepworth, "The biaxial load-extension behavior of a model of plain weft knitting. Part I," The Journal of the Textile Institute, vol. 69, pp. 101-107, 1978.

[7] R. Postle and D. L. Munden, "Analysis Of the dry-relaxed knitted-loop configuration-part II: three-dimensional analysis," Journal of the Textile Institute, vol. 58, no. 8, pp. 352-365, 1967.

[8] W. J. Shanahan and R. Postle, "Jamming of knitted structures," Textile Research Journal, vol. 43, no. 9, pp. 532-538, 1973.
[9] D. L. Munden, "The geometrical and dimensional properties of plain-knitted fabrics," Textile Research Journal, vol. 50, pp. 448471, 1959.

[10] D. L. Munden, "Specification of construction of knitted fabrics," Textile Research Journal, vol. 50, pp. 448-471, 1962.

[11] B. Karaguzel, Characterization and Role of Porosity in Knitted Fabrics, Department of Textile Engineering, Chemistry and Science, Raleigh, NC, USA, 2004.

[12] B. Wilbik-Halgas, R. Danych, B. Wiecek, and K. Kowalski, "Air and water vapour permeability in double-layered knitted fabrics with different raw materials," Fibresand Textiles in Eastern Europe, vol. 14, no. 3, pp. 77-80, 2004.

[13] F. Benltoufa Fayala, M. Cheikhrouhou, and S. B. Nasrallah, "Porosity determination of jersey structure," AUTEX Research Journal, vol. 7, article 63, 2007.

[14] T. Dias and G. B. Delkumburewatte, "Analysis of water absorbency into knitted spacer structures," Journal of the Textile Institute, vol. 101, no. 2, pp. 143-153, 2010.

[15] R. T. Ogulata and S. Mavruz, "Investigation of porosity and air permeability values of plain knitted fabrics," Fibres and Textiles in Eastern Europe, vol. 82, no. 5, pp. 71-75, 2010.

[16] ASTM, "Standard test method for wale and course count of weft knitted fabrics," ASTM D8007-15e1, ASTM International, West Conshohocken, Pa, USA, 2015, http://www.astm.org.

[17] IS, "Methods for determination of threads per unit length in knitted fabrics," IS 1963: 1982, Bureau of Indian Standards, New Delhi, India, 1982.

[18] R. Postle, The geometry of the relaxed plain-knit structure [Ph.D. thesis], University of Leeds, Leeds, UK, 1965.

[19] A. R. Horrocks and S. C. Anand, Eds., Handbook of Technical Textiles, chapter 5, Woodhead Publishing Limited, Cambridge, UK, 2000.

[20] I. Algaba, A. Riva, and P. C. Crews, "Influence of fiber type and fabric porosity on the UPF of summer fabrics," AATCC Review, vol. 4, no. 2, pp. 26-31, 2004. 

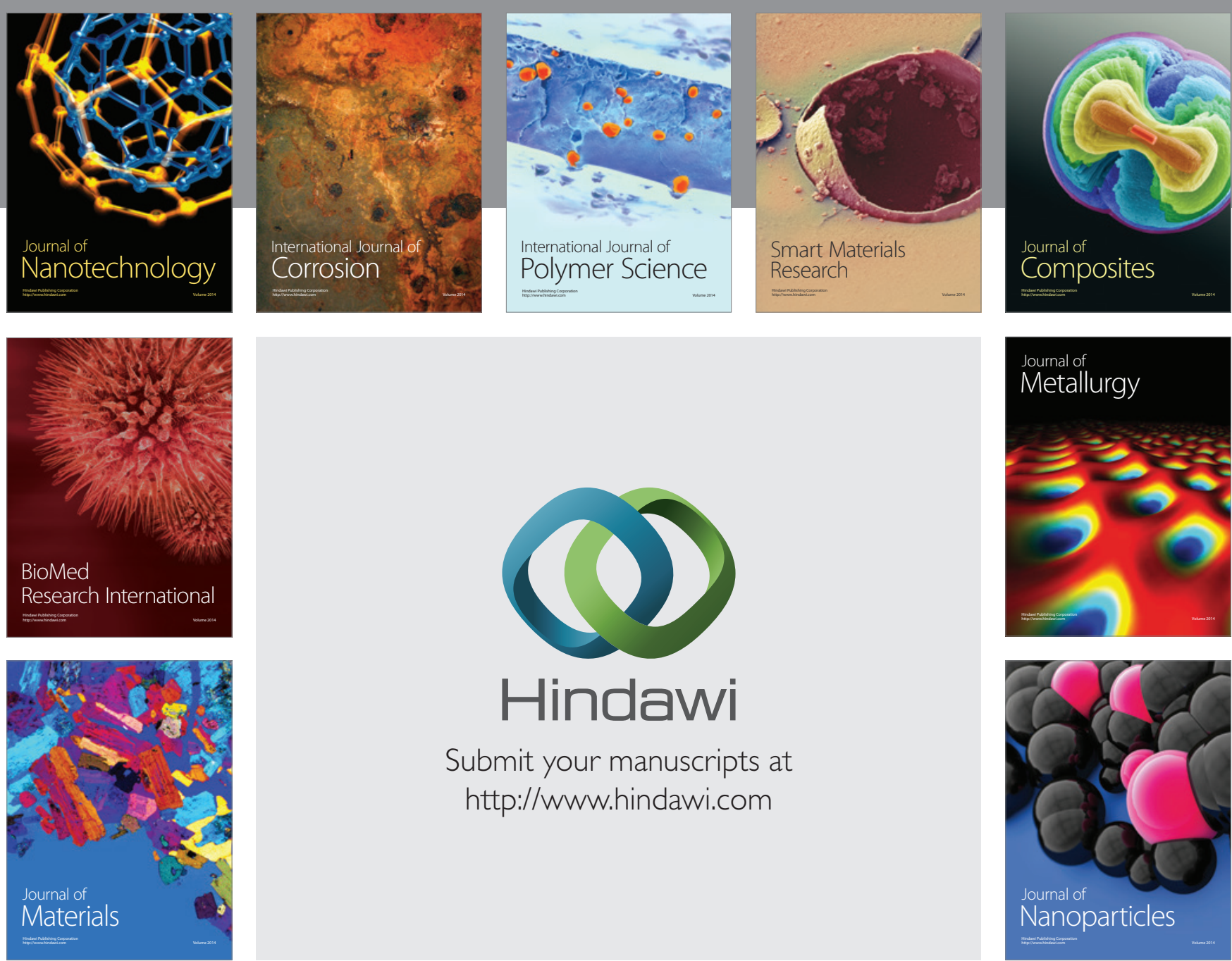

\section{Hindawi}

Submit your manuscripts at

http://www.hindawi.com

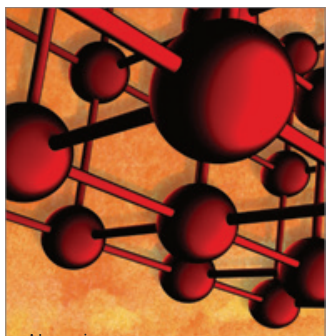

Materials Science and Engineering
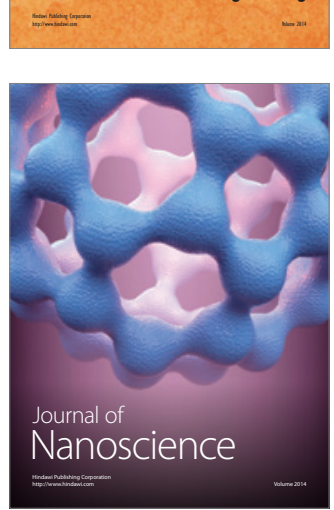
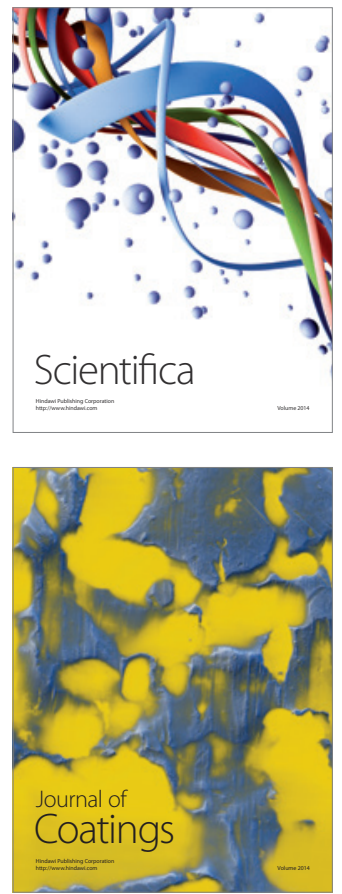
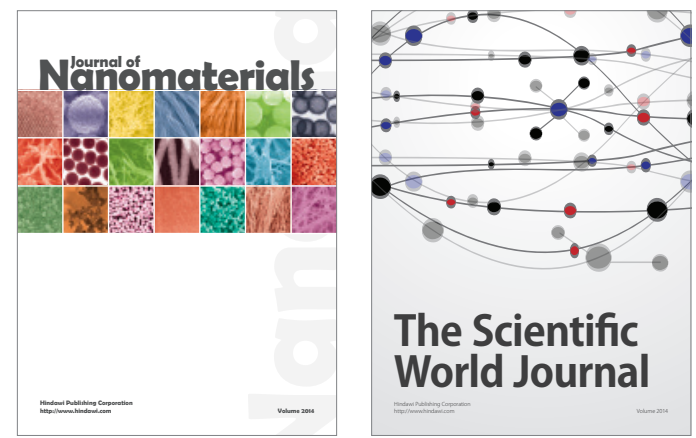

The Scientific World Journal
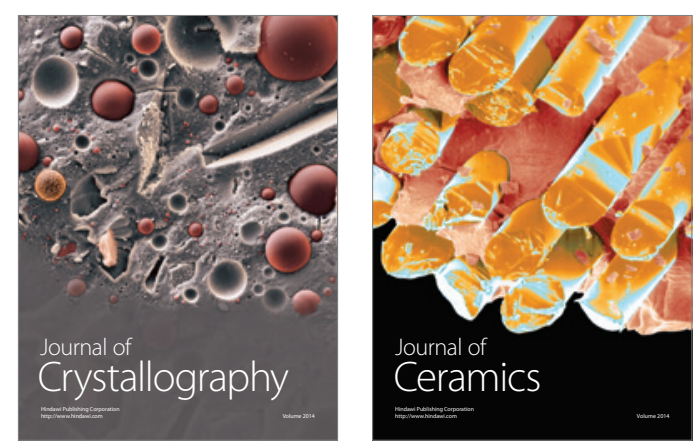
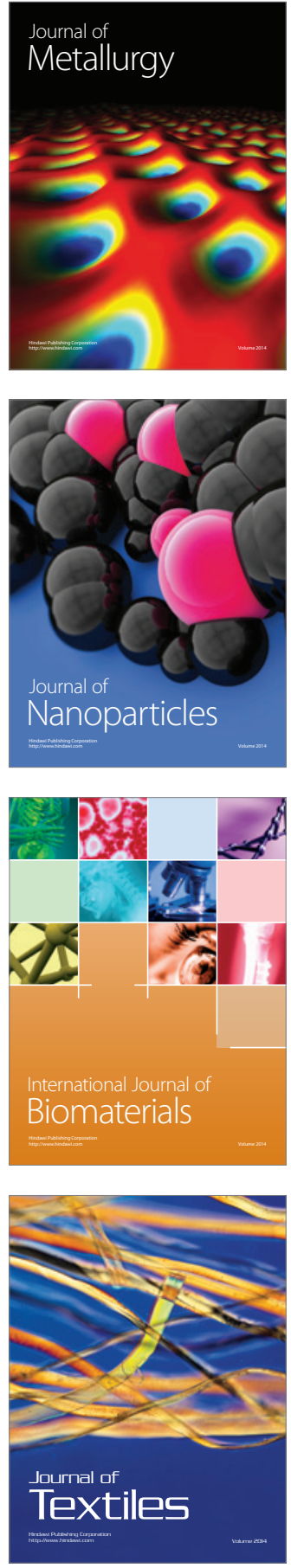